\title{
Перший досвід використання ботулотоксину типу А при хірургічному лікуванні вентральних гриж
}

\begin{abstract}
Мета роботи: вивчити досвід використання ботулотоксину типу А при хірургічному лікуванні вентральних гриж.
Матеріали і методи. У клініці кафедри загальної хірургії № 2 Національного медичного університету імені О. О. Богомольця проведено проспективне дослідження, що включало 9 пацієнта. Всі хворі проходили лікування в період з червня 2017 по грудень 2018 року з приводу вентральної грижі. У 7 (77,8 \%) пацієнтів було діагностовано післяопераційну вентральну грижу, у 1 (11,1%) пацієнта - рецидивну післяопераційну вентральну грижу, у 1 (11,1 \%) пацієнта - гігантську вентральну грижу білої лінії живота. Всім хворим як передопераційну підготовку було проведено ін'єкцію ботулотоксину типу А в м’язи передньої черевної стінки. Зміни щодо розмірів грижового дефекту оцінювали через 4 тижні з моменту ін’єкції за допомогою об’єктивного обстеження, ультразвукового дослідження та комп’ютерної томографії черевної стінки.

Результати досліджень та їх обговорення. Через 4 тижні після внутрішньом’язового введення ботулотоксину типу А у всіх пацієнтів за даними комп’ютерної томографії спостерігалося достовірне зменшення розмірів грижового дефекту (р<0,001). В середньому товщина черевної стінки справа зменшилася на $(1,45 \pm 1,05)$ мм, зліва - на $(1,22 \pm 0,97)$ мм. Спостерігалося достовірне збільшення довжини м’язів передньої черевної стінки в середньому на $(16,68 \pm 12,84)$ мм справа та на $(16,54 \pm 11,65)$ мм зліва. Використання ботулотоксину під час передопераційної підготовки дозволило уникнути сепараційних методів герніопластики у всіх пацієнтів та у 55,6 \% випадків виконати ушивання грижового дефекту та герніопластику лапароскопічно.
\end{abstract}

Ключові слова: грижа; ботулотоксин; герніопластика.

Постановка проблеми і аналіз останніх досліджень та публікацій. Однією з найпоширеніших патологій в хірургії є грижі передньої черевної стінки. Лідируючу позицію згідно з епідеміологічними дослідженнями займають саме грижі серединної ділянки. Частота захворюваності на пупкові та параумбілікальні грижі є найвищою та сягає $19 \%$. Грижі білої лінії живота в епігастральній ділянці зустрічаються у 8,6 \% випадків [1]. Дані щодо захворюваності на післяопераційні вентральні грижі коливаються в широких межах від 5,6 до 69 \% випадків залежно від супутніх ускладнюючих факторів. Однак у середньому в 10-20 \% випадків спостерігається розвиток грижі після виконання лапаротомії [2-5].

Основним методом лікування гриж передньої черевної стінки $є$ герніопластика з використанням алотрансплантата - сітки. Оптимальним при розмірах грижового дефекту до 10 см є виконання лапароскопічної герніопластики. [6]. При розмірах грижових воріт більше 10 см виникають труднощі щодо ушивання дефекту передньої черевної стінки без натягу. Виконання герніоалопластики за методикою Ramirez в різних модифікаціях $є$ травматичною та підвищує ризик розвитку післяопераційних ускладнень, в т. ч. у зоні післяопераційної рани $[7,8]$.

В 2009 році Ibarra-Hurtado TR et al. було опубліковано роботу, де пропонувалося застосовувати ботулотоксин типу А в передопераційному періоді з метою розслаблення та зниження тонусу м'язів передньої черевної стінки у пацієнтів 3 вентральними грижами [9]. Був запропонований принципово новий підхід до підготовки передньої черевної стінки для ушивання грижового дефекту великих розмірів. В основу покладено ідею збільшення довжини м'язів черевної стінки за рахунок їх розслаблення при блокуванні ботулотоксином типу А нервово-м'язової передачі нервового імпульсу. Впродовж останніх 10 років в літературі існують одиничні публікації, присвячені введенню ботулотоксину типу А у пацієнтів з грижами [10].

Мета роботи: вивчити досвід використання ботулотоксину типу А при хірургічному лікуванні вентральних гриж.

Матеріали і методи. В клініці кафедри загальної хірургії № 2 Національного медичного університету імені О. О. Богомольця було проведено проспективне дослідження, яке включало 9 пацієнтів, що проходили лікування в період з червня 2017 по грудень 2018 року. У 7 (77,8 \%) пацієнтів було діагностовано післяопераційну вентральну грижу, у 1 (11,1 \%) пацієнта - рецидивну післяопераційну вентральну грижу, у 1 (11,1 \%) пацієнта - гігантську вентральну грижу білої лінії живота. Середній вік хворих складав $(57,8 \pm 11,7)$ року (мінімальний -43 , максимальний -79 ). Жінок було 5 (55,5 \%), чоловіків - 4 (44,5 \%). 
Тип та розміри грижових дефектів визначалися відповідно до класифікації післяопераційних вентральних гриж, запропонованої Європейським товариством герніологів в 2009 році [11]. 39 пацієнтів, у 4 (44,4 \%) тип грижі був M3-M4, у 3 (33,3 \%) - тип грижі M2-M3, у 2 (22,3 \%) - тип грижі M2-M3-M4. У всіх пацієнтів розмір ширини грижового дефекту при об'єктивному обстеженні перевищував 10 см. Середній показник ширини грижового дефекту становив $(109,63 \pm 41,06)$ мм. Середній показник довжини грижового дефекту склав $(124,38 \pm 48,61)$ мм.

Всім пацієнтам в передопераційному періоді було виконано ін'єкції ботулотоксину типу А в м'язи передньої черевної стінки. Визначення локалізації та розмірів грижових дефектів, а також визначення точок введення ботулотоксину типу А проводили за допомогою ультразвукового дослідження передньої черевної стінки в режимі реального часу.

3 метою покращення точності введення ботулотоксину безпосередньо в м'язову тканину препарат вводили за допомогою ін'єкційної голки, приєднаної до нейростимулятора Стимуплекс HNS-12 (BBRAUN). Всім пацієнтам було введено 100 ОД ботулотоксину типу А (БОТОКС, Аллерган, США) в розведенні на 10 мл 0,9 \% розчину $\mathrm{NaCl}$. Під контролем ультразвукового дослідження лінійним датчиком в режимі реального часу виконували введення ботулотоксину типу А в м’язи передньої черевної стінки. 3 метою покращення точності введення ботулотоксину безпосередньо в м'язову тканину препарат вводили за допомогою ін'єкційної голки, приєднаної до нейростимулятора. Визначали 6 точок для ін'єкції ботулотоксину типу А в лівий та правий поперечний, зовнішній та внутрішній косі м'язи живота, по 1 точці в кожен 3 м'язів. Під контролем ультразвуку виконували пункцію обраного м'яза, за допомогою нейростимулятора та візуального контролю впевнювалися в розташуванні кінця ін'єкційної голки в товщі обраного м'яза, після чого розпочинали введення ботулотоксину типу А. За основу було обрано наступну методику введення препарату в м'язи передньої черевної стінки, всього 6 точок введення:

- у правий зовнішній косий м'яз живота - по лінії між передньою аксилярною та середньо-ключичною лініями на 4 см вище пупка справа, 15 Од;

- у правий поперечний м'яз живота - по правій середньо-ключичній лінії на рівні пупка, 15 Од;

- у правий внутрішній косий м'яз живота - по правій середньо-ключичній лінії на 3 см нижче пупка, 20 Од;
- у лівий зовнішній косий м'яз живота - по лінії між передньою аксилярною та середньо-ключичною лініями на 4 см вище пупка зліва, 15 Од,

- у лівий поперечний м'яз живота - по лівій середньо-ключичній лінії на рівні пупка, 15 Од;

- у лівий внутрішній косий м'яз живота - по лівій середньо-ключичній лінії на 3 см нижче пупка, 20 Од.

Після маніпуляції через 4 тижні виконували планове оперативне втручання - алогерніопластику, у т. ч. лапароскопічно, з ушиванням грижового дефекту.

Також з метою об'єктивізації дослідження та отримання даних щодо змін довжини м'язів черевної стінки пацієнтам виконували комп'ютерну томографію органів черевної порожнини до та через 4 тижні після введенням ботулотоксину типу А.

Результати досліджень та їх обговорення. В усіх 9 пацієнтів розвитку ускладнень під час та після введення ботулотоксину типу А у м'язи передньої черевної стінки не спостерігалося.

Через 4 тижні після внутрішньом'язового введення ботулотоксину типу А у всіх пацієнтів за даними комп’ютерної томографії спостерігалося достовірне зменшення розмірів грижового дефекту $(\mathrm{p}<0,001)$. В середньому по ширині грижовий дефект зменшився 3 на $(109,63 \pm 41,06)$ мм до $(97,13 \pm 38,73)$ мм.

Також проводили вимірювання товщини черевної стінки справа та зліва в симетричних точках. До введення ботулотоксину типу А середня товщина черевної стінки справа становила $(18,38$ $\pm 2,22)$ мм, через 4 тижні після - $(16,93 \pm 2,78)$ мм, динаміка набула ступеня статистичної значущості, $\mathrm{p}=0,006$. Середня товщина черевної стінки зліва до введення ботулотоксину типу А становила $(17,13 \pm 2,56)$ мм, через 4 тижні після - $(15,92$ $\pm 2,88)$ мм, динаміка набула ступеня статистичної значущості, $\mathrm{p}=0,009$. В середньому товщина черевної стінки справа зменшилася на $(1,45 \pm$ $1,05)$ мм, зліва - на $(1,22 \pm 0,97)$ мм.

При вимірюванні довжини м'язів черевної стінки визначали показники справа та зліва та рівня грижового дефекту, використовуючи зіставні поперечні зрізи черевної порожнини за даними комп’ютерної томографії. До введення ботулотоксину типу А довжина м'язів черевної стінки справа була достовірно меншою $(\mathrm{p}=0,008)$ порівняно $з$ аналогічним показником через 4 тижні після введення та в середньому становила $(252,09 \pm$ $65,12)$ мм. Після введення ботулотоксину довжина м'язів збільшувалася та в середньому становила $(268,76 \pm 71,72)$ мм. Довжина м’язів передньої 


\section{З ДОСВІДУ РОБОТИ}

черевної стінки зліва до введення ботулотоксину складала $(227,81 \pm 60,50)$ мм, через 4 тижні після $(244,35 \pm 65,96)$ мм (p=0,005). Спостерігалося достовірне збільшення довжини м’язів передньої черевної стінки в середньому на $(16,68 \pm 12,84)$ мм справа та на $(16,54 \pm 11,65)$ мм зліва.

Аналіз отриманих результатів продемонстрував зменшення розміру грижового дефекту, зростання довжини м’язів передньої черевної стінки та зменшення їх товщини через 4 тижні після введення 100 ОД ботулотоксину типу А.

На 4-5 тиждень 3 моменту введення ботулотоксину типу А у м’язи черевної стінки всім пацієнтам було виконано оперативне втручання. У 4 (44,4 \%) пацієнтів було виконано “відкриту” герніопластику. При цьому в 1 (11,1%) випадку алотрансплантат було встановлено за методикою sublay, в 3 (33,3 \%) випадках - за методикою IPOM. 5 (55,6%) пацієнтам було проведено лапароскопічний вісцероліз,

\section{СПИСОК ЛІТЕРАТУРИ}

1. Frequency of abdominal wall hernias: is classical teaching out of date? / N. Dabbas, K. Adams, K. Pearson, G. Royle // JRSM Short Reports. - 2011. - Vol. 2 (1). - P. 1-6. doi: 10.1258/ shorts.2010.010071.

2. Interrupted or continuous slowly absorbable sutures for closure of primary elective midline abdominal incisions / C. Seiler, T. Bruckner, M. Diener [et al.] // Annals of Surgery. - 2009. Vol. 249 (4). - P. 576-582. doi: 10.1097/sla.0b013e31819ec6c8. 3. Mudge M. Incisional hernia: A 10 year prospective study of incidence and attitudes / M. Mudge, L. Hughes // British Journal of Surgery. - 1985. - Vol. 72 (1). - P. 70-71. doi: 10.1002/ bjs.1800720127.

4. Retrospective review of risk factors for surgical wound dehiscence and incisional hernia / S. Walming, E. Angenete, M. Block [et al.] // BMC Surgery. - 2017. - Vol. 17 (1). doi: 10.1186/s12893-017-0207-0.

5. (2012). Incisional hernia postrepair of abdominal aortic occlusive and aneurysmal disease: five-year incidence / S. Alnassar, M. Bawahab, A. Abdoh [et al.] // Vascular. - 2012. Vol. 20 (5). - P. 273-277. doi: 10.1258/vasc.2011.oa0332.

6. Guidelines for laparoscopic treatment of ventral and incisional ушивання грижового дефекту окремими вузловими швами, герніопластику за методикою IPOM. Сепараційні методи герніопластики в жодному з випадків не застосовувались. До та інтраопераційно всім пацієнтам проводили вимірювання внутрішньочеревного тиску, показники якого коливалися в межах норми, без ознак внутрішньочеревної гіпертензіі. В період 12 міс. спостереження рецидиву захворювання не спостерігалося.

Висновки. Введення ботулотоксину типу А в м’язи передньої черевної стінки є технічно простим, малотравматичним способом збільшення еластичності та довжини м'язів з метою створення умов для закриття грижового дефекту при хірургічному лікуванні вентральних гриж великих розмірів, без натягу тканин передньої черевної стінки та з мінімізацією ризику підвищення внутрішньочеревного тиску. abdominal wall hernias (International Endohernia Society (IEHS)—Part 1 / R. Bittner, J. Bingener-Casey, U. Dietz [et al.] // Surgical Endoscopy. - 2013. - Vol. 28 (1). - P. 2-29. doi: 10.1007/s00464-013-3170-6.

7. Фелештинський Я. П. Післяопераційні грижі живота / Я. П. Фелештинський. - Київ, 2012. - 200с.

8. Faylona J. Evolution of ventral hernia repair / J. Faylona // Asian Journal of Endoscopic Surgery. - 2017. - Vol. 10 (3). P. 252-258. doi: 10.1111/ases.12392.

9. Use of botulinum toxin type A before abdominal wall hernia reconstruction / T. Ibarra-Hurtado, C. Nuño-Guzmán, J. Echeagaray-Herrera [et al.] // World Journal of Surgery. - 2009. - Vol. 33 (12). - P. 2553-2556. doi: 10.1007/s00268-009-0203-3. 10. Soltanizadeh S. Botulinum toxin A as an adjunct to abdominal wall reconstruction for incisional hernia / S. Soltanizadeh, F. Helgstrand, L. Jorgensen // Plastic and Reconstructive Surgery - Global Open. - 2017. - Vol. 5 (6). - e1358. doi: 10.1097/ gox. 0000000000001358 .

11. Classification of primary and incisional abdominal wall hernias / F. Muysoms, M. Miserez, F. Berrevoet [et al.] // Hernia. - 2009. Vol. 13 (4). - P. 407-414. doi: 10.1007/s10029-009-0518-x.

\section{REFERENCES}

1. Dabbas, N., Adams, K., Pearson, K., \& Royle, G. (2011). Frequency of abdominal wall hernias: is classical teaching out of date? JRSM Short Reports, 2 (1), 1-6. doi: 10.1258/ shorts.2010.010071.

2. Seiler, C., Bruckner, T., Diener, M., Papyan, A., Golcher, H., \& Seidlmayer, C. et al. (2009). Interrupted or continuous slowly absorbable sutures for closure of primary elective midline abdominal incisions. Annals of Surgery, 249 (4), 576-582. doi: 10.1097/sla.0b013e31819ec6c8.

3. Mudge, M., \& Hughes, L. (1985). Incisional hernia: A 10 year prospective study of incidence and attitudes. British Journal of Surgery, 72 (1), 70-71. doi: 10.1002/bjs.1800720127.

4. Walming, S., Angenete, E., Block, M., Bock, D., Gessler, B., \& Haglind, E. (2017). Retrospective review of risk factors for surgical wound dehiscence and incisional hernia. BMC Surgery, 17 (1). doi: 10.1186/s12893-017-0207-0.

5. Alnassar, S., Bawahab, M., Abdoh, A., Guzman, R., Al Tuwaijiri, T., \& Louridas, G. (2012). Incisional hernia postrepair of abdominal aortic occlusive and aneurysmal disease: five-year incidence. Vascular, 20 (5), 273-277. doi: 10.1258/vasc.2011. oa0332.

6. Bittner, R., Bingener-Casey, J., Dietz, U., Fabian, M., Ferzli, G., \& Fortelny, R. et al. (2013). Guidelines for laparoscopic treatment of ventral and incisional abdominal wall hernias (International 
Endohernia Society (IEHS)—Part 1. Surgical Endoscopy, 28 (1), 2-29. doi: 10.1007/s00464-013-3170-6.

7. Feleshtynskyi, Ya.P. (2012). Pisliaoperatsiini hryzhi zhyvota [Postoperative abdominal hernias]. Kyiv [in Ukrainian].

8. Faylona, J. (2017). Evolution of ventral hernia repair. Asian Journal of Endoscopic Surgery, 10 (3), 252-258. doi: 10.1111/ ases.12392.

9. Ibarra-Hurtado, T., Nuño-Guzmán, C., Echeagaray-Herrera, J., Robles-Vélez, E., \& de Jesús González-Jaime, J. (2009). Use of botulinum toxin type A before abdominal wall hernia reconstruction. World Journal of Surgery, 33 (12), 2553-2556. doi: 10.1007/s00268-009-0203-3.

10. Soltanizadeh, S., Helgstrand, F., \& Jorgensen, L. (2017). Botulinum toxin $\mathrm{A}$ as an adjunct to abdominal wall reconstruction for incisional hernia. Plastic and Reconstructive Surgery - Global Open, 5 (6), e1358. doi: 10.1097/gox.0000000000001358.

11. Muysoms, F., Miserez, M., Berrevoet, F., Campanelli, G., Champault, G., \& Chelala, E. et al. (2009). Classification of primary and incisional abdominal wall hernias. Hernia, 13 (4), 407-414. doi: 10.1007/s10029-009-0518-x.

Електронна адреса для листування: mykola.stets@nти.иа

\author{
T. V. TARASIUK \\ O. Bohomolets National Medical University, Kyiv
}

\title{
THE FIRST EXPERIENCE OF USE BOTULINUM TOXIN TYPE A IN THE SURGICAL TREATMENT OF VENTRAL HERNIAS
}

\begin{abstract}
The aim of the work: to study the experience of using type A botulinum toxin in the surgical treatment of ventral hernias. Materials and Methods. In the clinic of the Department of General Surgery No. 2 of O. Bohomolets National Medical University a prospective study was conducted and included 9 patients. All patients underwent treatment from June 2017 to December 2018 for ventral hernia. In 7 (77.8 \%) patients, a postoperative ventral hernia was diagnosed, in 1 (11.1 \%) patient - a recurrent postoperative ventral hernia, in $1(11.1 \%)$ patient - a giant ventral hernia of the white line of the abdomen. All patients received an injection of type A botulinum toxin into the muscles of the anterior abdominal wall as a preoperative preparation. Changes regarding the size of the hernial defect were evaluated after 4 weeks from the moment of injection using objective examination, ultrasound and computed tomography of the abdominal wall. Results and Discussion. 4 weeks after the intramuscular injection of botulinum toxin type A, a significant decrease in the size of the hernial defect was observed in all patients according to computed tomography $(\mathrm{p}<0.001)$. On average, the thickness of the abdominal wall on the right side decreased by $(1.45 \pm 1.05) \mathrm{mm}$, on the left - by $(1.22 \pm 0.97) \mathrm{mm}$. A significant increase in the length of the muscles of the anterior abdominal wall was observed on average by $(16.68 \pm 12.84) \mathrm{mm}$ on the right side and $(16.54 \pm 11.65) \mathrm{mm}$ on the left side. The use of botulinum toxin in preoperative preparation made it possible to avoid separation methods of hernioplasty in all patients and in $55.6 \%$ of cases suturing of the hernial defect and hernioplasty were performed laparoscopically.
\end{abstract}

Key words: hernia; botulinum toxin; hernioplasty.

T. В. TAPACЮK

Национальный медицинский университет имени А. А. Богомольца, Киев

\section{ПЕРВЫЙ ОПЫТ ИСПОЛЬЗОВАНИЯ БОТУЛОТОКСИНА ТИПА А ПРИ ХИРУРГИЧЕСКОМ ЛЕЧЕНИИ ВЕНТРАЛЬНЫХ ГРЫ\%}

\begin{abstract}
Цель работы: изучить опыт использования ботулотоксина типа А при хирургическом лечении вентральных грыж. Материалы и методы. В клинике кафедры общей хирургии № 2 Национального медицинского университета имени А. А. Богомольца проведено проспективное исследование, включавшее 9 пациентов. Все больные проходили лечение в период с июня 2017 г. по декабрь 2018 г. по поводу вентральной грыжи. У 7 (77,8 \%) пациентов была диагностирована послеоперационная вентральная грыжа, у 1 (11,1 \%) пациента - рецидивная послеоперационная вентральная грыжа, у 1 (11,1 \%) пациента - гигантская вентральная грыжа белой линии живота. Всем больным в качестве предоперационной подготовки было проведено инъекцию ботулотоксина типа А в мышцы передней брюшной стенки. Изменения относительно размеров грыжевого дефекта оценивали через 4 недели с момента инъекции с помощью объективного обследования, ультразвукового исследования и компьютерной томографии брюшной стенки. Результаты исследований и их обсуждение. Через 4 недели после внутримышечного введения ботулотоксина типа А у всех пациентов по данным компьютерной томографии наблюдалось достоверное уменьшение размеров грыжевого дефекта $(\mathrm{p}<0,001)$. В среднем толщина брюшной стенки справа уменьшилась на $(1,45 \pm 1,05)$ мм, слева - на $(1,22 \pm 0,97)$ мм. Наблюдалось достоверное увеличение длины мышц передней брюшной стенки в среднем на $(16,68 \pm 12,84)$ мм справа и на $(16,54 \pm 11,65)$ мм слева. Использование ботулотоксина при предоперационной подготовке позволило избежать сепарационных методов герниопластики у всех пациентов и в 55,6 \% случаев выполнить ушивание грыжевого дефекта и герниопластику лапароскопически.
\end{abstract}

Ключевые слова: грыжа; ботулотоксин; герниопластика. 